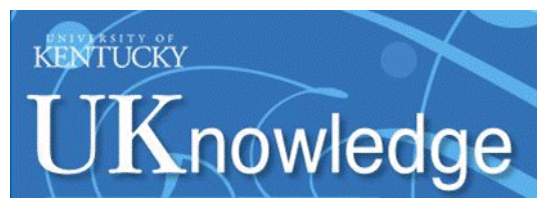

University of Kentucky

UKnowledge

Gill Heart \& Vascular Institute Faculty

Publications

Heart \& Vascular

5-16-2011

\title{
Lipid Phosphate Phosphatase 3 Enables Efficient Thymic Egress
}

\author{
Béatrice Bréart \\ New York University \\ Willy D. Ramos-Perez \\ New York University \\ Alejandra Mendoza \\ New York University \\ Abdelghaffar K. Salous \\ University of Kentucky, abdel.salous@uky.edu \\ Michael Gobert \\ New York University
}

See next page for additional authors

Follow this and additional works at: https://uknowledge.uky.edu/heart_facpub

Part of the Cardiology Commons

Right click to open a feedback form in a new tab to let us know how this document benefits you.

\section{Repository Citation}

Bréart, Béatrice; Ramos-Perez, Willy D.; Mendoza, Alejandra; Salous, Abdelghaffar K.; Gobert, Michael; Huang, Yong; Adams, Ralf H.; Lafaille, Juan J.; Escalante-Alcalde, Diana; Morris, Andrew J.; and Schwab, Susan R., "Lipid Phosphate Phosphatase 3 Enables Efficient Thymic Egress" (2011). Gill Heart \& Vascular Institute Faculty Publications. 5.

https://uknowledge.uky.edu/heart_facpub/5

This Article is brought to you for free and open access by the Heart \& Vascular at UKnowledge. It has been accepted for inclusion in Gill Heart \& Vascular Institute Faculty Publications by an authorized administrator of UKnowledge. For more information, please contact UKnowledge@lsv.uky.edu. 


\section{Lipid Phosphate Phosphatase 3 Enables Efficient Thymic Egress}

\section{Digital Object Identifier (DOI)}

http://dx.doi.org/10.1084/jem.20102551

\section{Notes/Citation Information}

Published in The Journal of Experimental Medicine, v. 208, no. 6, p. 1267-1278.

(C) 2011 Bréart et al.

This article is distributed under the terms of an Attribution-Noncommercial-Share Alike-No Mirror Sites license for the first six months after the publication date (see http://www.rupress.org/terms). After six months it is available under a Creative Commons License (Attribution-Noncommercial-Share Alike 3.0 Unported license, as described at http://creativecommons.org/licenses/by-nc-sa/3.0/).

\section{Authors}

Béatrice Bréart, Willy D. Ramos-Perez, Alejandra Mendoza, Abdelghaffar K. Salous, Michael Gobert, Yong Huang, Ralf H. Adams, Juan J. Lafaille, Diana Escalante-Alcalde, Andrew J. Morris, and Susan R. Schwab 


\title{
Lipid phosphate phosphatase 3 enables efficient thymic egress
}

\author{
Béatrice Bréart, ${ }^{1}$ Willy D. Ramos-Perez, ${ }^{1}$ Alejandra Mendoza, ${ }^{1}$ \\ Abdelghaffar K. Salous, ${ }^{2}$ Michael Gobert, ${ }^{1}$ Yong Huang, ${ }^{3}$ Ralf H. Adams, ${ }^{4,5}$ \\ Juan J. Lafaille, ${ }^{1}$ Diana Escalante-Alcalde, ${ }^{6}$ Andrew J. Morris, ${ }^{2}$ \\ and Susan R. Schwab ${ }^{1}$
}

'Program in Molecular Pathogenesis and Department of Pathology, Skirball Institute of Biomolecular Medicine, New York University School of Medicine, New York, NY 10016

2Division of Cardiovascular Medicine, Gill Heart Institute, University of Kentucky, Lexington, KY 40536

3Department of Bioengineering and Therapeutic Sciences, University of California, San Francisco, South San Francisco, CA 94080

${ }^{4}$ Department of Tissue Morphogenesis, Max Planck Institute for Molecular Biomedicine, 48149 Münster, Germany

${ }^{5}$ Faculty of Medicine, University of Münster, 48149 Münster, Germany

${ }^{6}$ División de Neurociencias, Instituto de Fisiología Celular, Universidad Nacional Autónoma de México, México City 04510, México

The signaling lipid sphingosine-1-phosphate (S1P) stabilizes the vasculature, directs lymphocyte egress from lymphoid organs, and shapes inflammatory responses. However, little is known about how S1P distribution is controlled in vivo, and it is not clear how a ubiquitously made lipid functions as a signal that requires precise spatial and temporal control. We have found that lipid phosphate phosphatase 3 (LPP3) enables efficient export of mature $T$ cells from the thymus into circulation, and several lines of evidence suggest that LPP3 promotes exit by destroying thymic S1P. Although five additional S1P-degrading enzymes are expressed in the thymus, they cannot compensate for the loss of LPP3. Moreover, conditional deletion of LPP3 in either epithelial cells or endothelial cells is sufficient to inhibit egress. These results suggest that S1P generation and destruction are tightly regulated and that LPP3 is essential to establish the balance.

\section{CORRESPONDENCE}

Susan R. Schwab:

Susan.Schwab@med.nyu.edu

Abbreviations used: CD4SP, CD4 single-positive; DN, double negative; DP, double positive; LPP3, lipid phosphate phosphatase 3; MFI, mean fluorescence intensity; $\mathrm{pIpC}$, polyinosinic:polycytidylic acid; S1P, sphingosine-1-phosphate; S1PR1, S1P receptor 1; SPP1, S1P phosphatase 1.
The signaling lipid sphingosine-1-phosphate (S1P) plays critical roles in mammalian biology. Extracellular S1P binds five G protein-coupled receptors, S1P receptors 1-5 (Hla, 2004), and intracellular S1P binds an expanding set of proteins (Hait et al., 2009; Alvarez et al., 2010; Puneet et al., 2010). The concentration of S1P is high in circulatory fluids, and plasma S1P stabilizes junctions between vascular endothelial cells (Lee et al., 1999; Kono et al., 2008; Camerer et al., 2009). The concentration of extracellular S1P is low in lymphoid tissues compared with blood and lymph, and this difference directs lymphocyte egress from lymphoid organs into circulation (Schwab and Cyster, 2007). Although extracellular S1P in lymphoid organs, and likely most tissues, is low in homeostasis, S1P may increase upon inflammation. Elevated S1P has been reported to promote angiogenesis and to enhance proinflammatory responses of innate and adaptive immune cells (Rivera et al., 2008; Liu et al., 2010). Drugs targeting S1P signaling are in clinical trials as immune suppressants
(Carroll, 2010). In fact, FTY720 has just been approved by the United States Food and Drug Administration for treatment of multiple sclerosis (Brinkmann et al., 2010). By blocking exit from lymphoid organs, these drugs prevent activated $\mathrm{T}$ cells from trafficking to organs under autoimmune attack. These drugs may also have direct antiinflammatory effects.

Despite its importance, little is known about how the distribution of S1P is controlled in vivo. This question is particularly interesting because it is difficult to understand how a ubiquitously made lipid functions as a signal that requires precise spatial and temporal control. To maintain low extracellular tissue S1P in homeostasis, several sources of S1P must be contained. First, all cells are thought to make S1P intracellularly as an intermediate in membrane

0 2011 Bréart et al. This article is distributed under the terms of an Attribution-Noncommercial-Share Alike-No Mirror Sites license for the first six months tion-Noncommercial-Share Alike-No Mirror Sites license for the first six months
after the publication date (see http://www.rupress.org/terms). After six months it is available under a Creative Commons License (Attribution-NoncommercialShare Alike 3.0 Unported license, as described at http://creativecommons.org/ licenses/by-nc-sa/3.0/) 
sphingolipid metabolism (Hannun and Obeid, 2008); metabolic S1P must be destroyed before it accumulates in the interstitial space. Second, plasma S1P must be excluded from the tissue. S1P concentrations in plasma are in the micromolar range, and although tissues are constantly bathed with transudated plasma to bring nutrients and remove waste, S1P in the interstitial fluid of lymphoid organs has been estimated to be sub-nanomolar (Schwab and Cyster, 2007). S1P's abundance suggests the possibility that levels could be changed rapidly in response to physiological cues and the requirement that its concentration be tightly regulated.

Many factors are undoubtedly required to maintain low tissue S1P, but one key is likely how S1P is degraded. Strikingly, not one but six enzymes are known to destroy S1P in vitro. These enzymes fall into two classes. The first consists of S1P lyase, which cleaves S1P to 2-hexadecenal and phosphoethanolamine, and S1P phosphatases 1 and 2, which dephosphorylate S1P to sphingosine (Saba and Hla, 2004). These three enzymes are thought to be highly specific for S1P and reside predominantly in the endoplasmic reticulum. S1P lyase is required to maintain low lymphoid organ S1P (Schwab et al., 2005). Although the source of S1P destroyed by S1P lyase is not known, it is likely to be S1P made in the course of sphingolipid metabolism; S1P lyase's intracellular location positions it well for this function. The second class of S1P-degrading enzymes consists of three phosphatases: lipid phosphate phosphatases 1,2, and 3 (Roberts et al., 1998; Brindley et al., 2000; Pyne et al., 2004). These enzymes can dephosphorylate a range of substrates, including S1P, ceramide-1-phosphate, lysophosphatidic acid, and phosphatidic acid. The lipid phosphate phosphatases have been shown in many cell types to localize to the plasma membrane with their active site facing outside the cell, well positioned to degrade extracellular lipid entering the tissues from the blood or secreted by tissue-resident cells. The role of the lipid phosphate phosphatases in controlling tissue S1P is largely unknown.

In this paper, we asked what is the role of lipid phosphate phosphatase 3 (LPP3; encoded by Ppap 2b) in regulating extracellular S1P within lymphoid organs. We found that LPP3 is essential to enable efficient export of mature $\mathrm{T}$ cells from the thymus to the blood, and several lines of evidence suggest that LPP3 promotes egress by maintaining low thymic S1P. Although all six S1P-degrading enzymes are expressed in the thymus, the loss of LPP3 alone in either epithelial cells or endothelial cells is sufficient to delay exit.

\section{RESULTS}

\section{LPP3 is required to keep thymic S1P low}

Because LPP3 is essential in embryonic development (EscalanteAlcalde et al., 2003), we used Ppap $2 b^{f f}$ mice to study the function of LPP3 in lymphoid organs (Escalante-Alcalde et al., 2007). We crossed in Cre recombinase driven by the interferon-inducible $M x 1$ promoter (Mx1-Cre; Kühn et al., 1995). Pups were treated with polyinosinic:polycytidylic acid (pI-pC) 3-5 d after birth to activate the $M x 1$ promoter and Cre expression. Adults were analyzed at least 6 wk later. This induction of Mx1-Cre mediates efficient deletion in a wide range of tissues and lineages, including hematopoietic cells and a subset of endothelial cells (Pappu et al., 2007). For simplicity, we refer to pI-pC-treated Ppap $2 b^{f /-} M x 1 \mathrm{Cre}^{+}$and Ppap $2 b^{f / f}$ $\mathrm{Mx} 1 \mathrm{Cre}^{+}$mice as LPP3 deficient. Littermate controls were pI-pC treated at the same time as LPP3-deficient mice and retained at least one intact copy of LPP3. To assess whether LPP3 regulates thymic S1P, we examined three parameters that are dependent on S1P signaling: the rate of exit of mature $\mathrm{T}$ cells from the thymus, the level of surface CD69 on mature thymocytes, and the level of surface S1P receptor 1 (S1PR1) on mature thymocytes.

\section{LPP3 deficiency impairs thymic egress}

We first asked whether egress of mature $\mathrm{T}$ cells from the thymus was impaired in LPP3-deficient mice. $\mathrm{T}$ cells must express S1PR1 to exit lymphoid organs into circulatory fluids (Allende et al., 2004; Matloubian et al., 2004; Weinreich and Hogquist, 2008). Furthermore, disruption of the S1P gradient, either by removing circulatory S1P (Pappu et al., 2007) or by raising lymphoid tissue S1P (Schwab et al., 2005), blocks egress. We expected that if thymic S1P were elevated in the absence of LPP3, exit would be slowed, resulting in an accumulation of mature $\mathrm{T}$ cells in the thymus.

We observed a 2.5 -fold increase in the percentage of mature CD4 single-positive (CD4SP) T cells $\left(\mathrm{CD} 4^{+} \mathrm{CD} 8^{-}\right.$ $\left.\mathrm{CD} 62 \mathrm{~L}^{\text {hi }} \mathrm{CD} 69^{\text {lo }}\right)$ among total $\mathrm{CD} 4 \mathrm{SP}\left(\mathrm{CD} 4^{+} \mathrm{CD} 8^{-}\right)$thymocytes in LPP3-deficient mice compared with littermate controls (Fig. 1, A and B). There is also an increase in the percentage of CD4SP T cells among total thymocytes. When we calculated absolute numbers, we found a 4.5 -fold increase of mature CD4SP T cells in the thymus of LPP3-deficient mice without any change in the number of immature CD4SP precursors (Fig. 1 C). The absolute numbers are more variable than the percentages, as the total size of the thymus varies with many factors including age and stress. Nonetheless, in each case the number of mature CD4SP was larger in the LPP3-deficient mouse than its littermate control. We saw no change in the number of double-negative (DN) T cells and a $30 \%$ reduction in the number of double-positive (DP) T cells in the thymus of LPP3-deficient mice compared with littermate controls (Fig. S1 A). As one might predict from a slowing of thymic egress, we saw a moderate reduction in the number of $\mathrm{T}$ cells in the periphery (Fig. S1 B). Mature CD8 singlepositive $\mathrm{T}$ cells similarly accumulate in the thymus of LPP3deficient mice (Fig. S1 C).

The accumulation of mature $\mathrm{T}$ cells suggests an egress block but could also result from enhanced proliferation of mature T cells. Developing T cells mature from the DN to the DP to the SP stage. In WT mice, thymocytes proliferate extensively as they transition from DN to DP and relatively infrequently at the SP stage (Egerton et al., 1990). To assess the possibility that mature SP T cells divide more frequently in LPP3-deficient mice, we treated mice continuously with the thymidine analogue $\mathrm{BrdU}$ in the drinking water to label proliferating cells. After $11 \mathrm{~d}$ of BrdU treatment, virtually all 

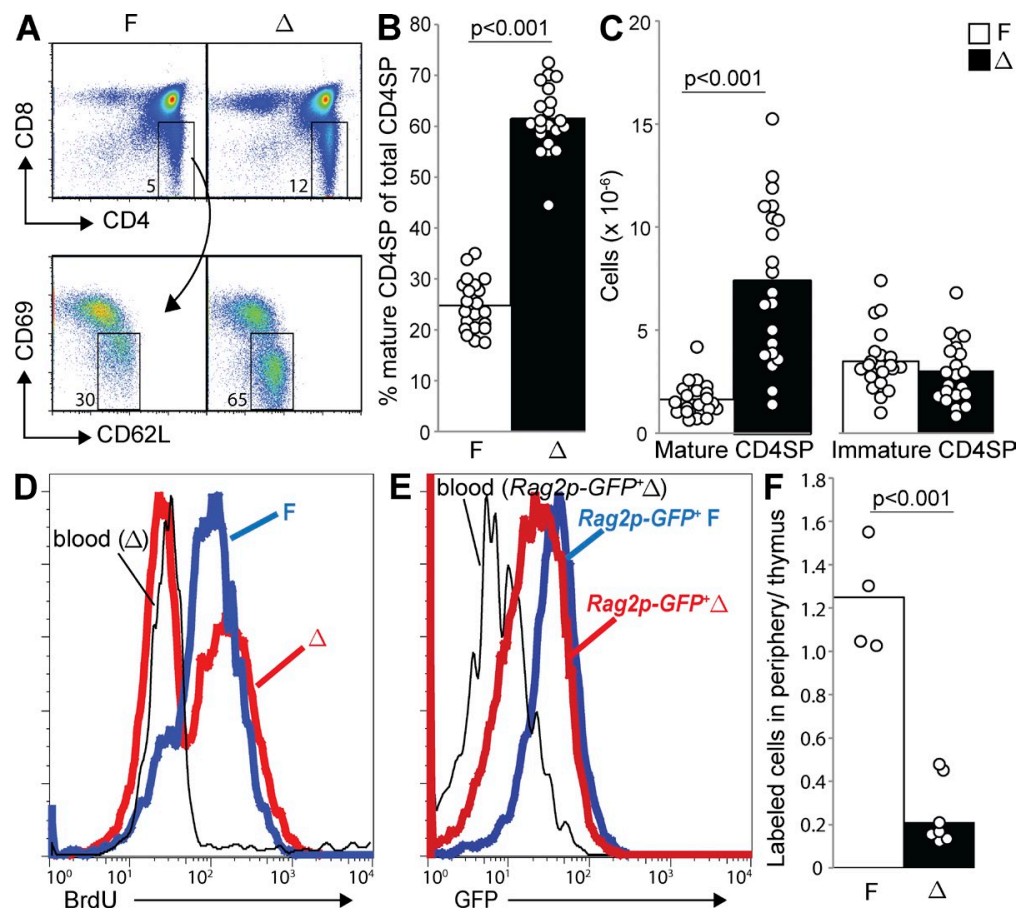

Figure 1. LPP3 is required for efficient thymic egress. LPP3-deficient mice $\left(\Delta_{i}\right.$ Ppap2 $b^{f /-} M \times 1 C r e^{+}$or Ppap2 $b^{f / f}$ $\mathrm{Mx} 1 \mathrm{Cre}^{+}$, treated with pl-pC 3-5d after birth) and littermate controls (F; Ppap2 $b^{f+} \mathrm{M} \times 1 \mathrm{Cre}^{+}$, Ppap2 $\mathrm{b}^{+/-} \mathrm{M} \times 1 \mathrm{Cre}^{+}$, Ppap2 $b^{f /-}$, Ppap2 $b^{f / f}$, Ppap2 $b^{f /+}$, or Ppap2 $b^{+/-}$, treated with pl-pC 3-5 d after birth at the same time as LPP3-deficient mice) were analyzed at 6 wk or older. (A) Expression of CD4 and CD8 by total thymocytes (top) and expression of CD69 and $\mathrm{CD} 62 \mathrm{~L}$ by $\mathrm{CD} 4 \mathrm{SP}\left(\mathrm{CD} 4^{+} \mathrm{CD} 8^{-}\right)$thymocytes (bottom) from a representative $L P P 3$-deficient mouse $(\Delta)$ and littermate control (F). (B) Percentage of mature CD4SP thymocytes (CD4+CD8 ${ }^{-} \mathrm{CD}^{+} \mathrm{L}^{\text {hi }}{ }^{\mathrm{CD}} 69^{10}$ ) among total CD4SP thymocytes. (C) Total number of mature CD4SP thymocytes and immature CD4SP thymocytes (CD4 $\left.{ }^{+} \mathrm{CD} 8{ }^{-} \mathrm{CD} 62 \mathrm{~L}^{\mathrm{lo}} \mathrm{CD} 69^{\mathrm{hi}}\right)$. In $\mathrm{B}$ and $C_{1}$ each point represents an individual mouse and bars show the mean. Graphs are a compilation of 13 experiments with a total of 21 mice per group. In all figures, $p$-values were calculated using the two-tailed unpaired Student's $t$ test. (D) LPP3-deficient mice and littermate controls were treated with $0.8 \mathrm{mg} / \mathrm{ml} \mathrm{BrdU}$ in the drinking water for $11 \mathrm{~d}$. BrdU incorporation by mature CD4SP thymocytes, as well as naive blood CD4 ${ }^{+} T$ cells, was measured by flow cytometry. Data are representative of three pairs of mice analyzed in three experiments. (E) GFP levels of mature CD4SP thymocytes from a representative Rag2p-GFP+ LPP3-deficient $(\Delta)$ mouse, mature CD4SP thymocytes from its Rag2p-GFP+ littermate

control (F), and naive (CD69 $\left.\mathrm{L}^{\text {hi }} \mathrm{CD} 69^{\circ}\right)$ CD4+ $\mathrm{T}$ cells from the blood of the LPP3-deficient Rag2p-GFP+ mouse, measured by flow cytometry. Data are representative of four pairs of mice analyzed in two experiments. (F) Sulfo-NHS biotin was injected into the thymus of LPP3-deficient mice and littermate controls. $16 \mathrm{~h}$ later, biotin-labeled mature CD4SP T cells in the thymus and CD4+ T cells in the periphery (combined blood, spleen, mesenteric, inguinal, axillary, and brachial LNs) were enumerated. The graph shows the ratio of the number of labeled cells in the periphery to the number of labeled cells remaining in the thymus. Each point represents an individual mouse and bars show the mean. The graph compiles data from seven LPP3-deficient mice and four littermate controls analyzed in two experiments. Mature T cells in the thymus of LPP3-deficient and littermate controls were labeled with similar efficiency (mean 57 and 62\%, respectively).

mature CD4SP T cells in control mice were $\mathrm{BrdU}^{+}$(Fig. 1 D). In contrast, in LPP3-deficient mice a substantial number of mature CD4SP T cells remained unlabeled (Fig. 1 D). The increased fraction of $\mathrm{BrdU}^{-}$mature SP T cells is inconsistent with enhanced proliferation of mature SP thymocytes in LPP3deficient mice. Instead, it is consistent with delayed egress; the $\mathrm{BrdU}^{-}$cells likely developed before the labeling period began and remained in the thymus for an extended period. Mature CD8SP T cells had a similar pattern (Fig. S1 D).

Although an accumulation of mature $\mathrm{T}$ cells in the absence of proliferation is consistent with a failure to exit, it is also possible that this could reflect enhanced reentry of peripheral $\mathrm{T}$ cells into the thymus. To distinguish between these possibilities, we took advantage of $\operatorname{Rag} 2 p$-GFP reporter mice (Yu et al., 1999; Boursalian et al., 2004). In these mice, GFP transcription is driven by the Rag2 promoter. After RAG is turned off at the DP stage, GFP protein levels decay with a half-life of $\sim 56 \mathrm{~h}$ (McCaughtry et al., 2007). GFP acts as a clock, with its abundance reflecting the amount of time that has passed since positive selection. Analysis of LPP3-deficient Rag $2 p$ $G F P^{+}$mice and Rag $2 p-G F P^{+}$littermate controls revealed that mature CD4SP LPP3-deficient thymocytes have lower GFP than mature CD4SP control thymocytes but higher GFP than naive CD4T cells circulating in the periphery (Fig. 1 E). Mature CD8SP T cells behave similarly (Fig. S1 E). This pattern is consistent with prolonged thymic residence and delayed egress but not with reentry of peripheral $\mathrm{T}$ cells.

Finally, we directly tested the efficiency of thymic egress by injecting sulfo-NHS biotin into the thymus of LPP3deficient mice and littermate controls and tracking the appearance of labeled cells in the periphery. To minimize inflammation, we used ultrasound to guide the injection needle (Blair-Handon et al., 2010). After 16 h, we found that the ratio of labeled $\mathrm{CD} 4^{+} \mathrm{T}$ cells in the periphery (pooled blood, spleen, and LNs) to labeled mature CD4SP T cells remaining in the thymus was $\sim 0.2$ in LPP3-deficient mice and 1.3 in controls (Fig. 1 F). Approximately twofold fewer labeled cells had emigrated to the periphery in LPP3-deficient mice, whereas threefold more labeled cells stayed in the thymus. These results are again consistent with an exit defect.

\section{LPP3 deficiency causes down-modulation of CD69 on mature T cells}

Our second indication that LPP3 regulates thymic S1P was the level of the activation marker CD69 on mature SP thymocytes. Mature SP T cells normally express intermediate levels of CD69, as they have recently completed positive selection, but S1P signaling causes rapid down-modulation of surface CD69. This observation was first made in mice treated with the $\mathrm{S} 1 \mathrm{P}$ receptor agonist AAL-(R) (Rosen et al., 2003) and 
reproduced in mice treated with the S1PR1-selective agonist SEW2871 (Alfonso et al., 2006). CD69 and S1PR1 interact, and S1PR1 mediates CD69 internalization in a pertussis toxinsensitive manner (Shiow et al., 2006). CD69 is down-modulated on mature but not immature SP T cells. S1pr1 mRNA is $>10$-fold more abundant in mature than in immature CD4SP thymocytes (Matloubian et al., 2004), and surface S1PR1 protein is readily detectable on mature but not immature SP T cells (Zachariah and Cyster, 2010). We expected that if S1P were elevated in the thymus of LPP3-deficient mice, surface CD69 on mature SP T cells would decrease.

We observed down-modulation of CD69 on the surface of mature SP T cells in LPP3-deficient animals compared with littermate controls (Fig. 1 A). To pool experiments, we calculated the ratio of CD69 mean fluorescence intensity (MFI) of littermate control mature CD4SP thymocytes/ CD69 MFI of LPP3-deficient mature CD4SP thymocytes. This ratio was $\sim 3$ (Fig. 2 A). The down-modulation of CD69 on mature $\mathrm{T}$ cells in LPP3-deficient mice is not simply secondary to a longer residence time, as it was also seen on the recently mature GFPhi cells in LPP3-deficient Rag2p-GFP mice (Fig. 2 B). The decreased CD69 on mature T cells is also not the result of a failure to up-regulate fully CD69 during positive selection, as we saw no difference in the level of CD69 on immature CD4SP T cells from LPP3-deficient mice and littermate controls (Figs. $1 \mathrm{~A}$ and $2 \mathrm{C}$ ).

\section{LPP3 deficiency causes internalization of S1PR1}

Our third test of whether LPP3 is required to maintain low extracellular thymic S1P was the level of surface S1PR1 on mature SP T cells. Mature SP T cells normally express abundant S1PR1, enabling them to exit the thymus efficiently (Matloubian et al., 2004). S1PR1 is internalized upon binding S1P (Liu et al., 1999; Schwab et al., 2005), and we expected that if LPP3-deficient mice had elevated thymic S1P, surface S1PR1 on thymic T cells would be reduced.

We found that the level of S1PR1 is two- to threefold lower on the surface of mature SP thymocytes of LPP3-deficient mice than littermate controls (Fig. 2 D). S1pr1 transcript is comparable between LPP3-deficient and littermate control mice, suggesting that the decrease is posttranscriptional (Fig. S2 A). CCR7 surface protein also does not differ between LPP3deficient and littermate control mice, suggesting that the decrease does not reflect a global down-modulation of $G$ protein-coupled receptors (Fig. S2 B).

Collectively, the egress block, CD69 down-modulation, and reduction in surface S1PR1 strongly suggest that the S1Pdegrading enzyme LPP3 is required to maintain low thymic S1P. Using mass spectrometry, we were unable to detect elevated S1P in whole thymic tissue of LPP3-deficient mice (Fig. S2C), which is not surprising given the incomplete down-modulation of S1PR1. The concentration of S1P in the thymus of control animals is $\sim 0.5 \mathrm{pmol} / \mathrm{mg}$ wet weight, which translates to $500 \mathrm{nM}$ assuming that the density of the thymus is the same as water (an underestimate). This is consistent with previous measurements of S1P in the whole embryo (Mizugishi et al., 2005). In contrast to the total level of S1P in the thymus, $10 \mathrm{nM}$ of extracellular S1P is sufficient to decrease surface S1PR1 on mature thymocytes to below our limit of detection (Schwab et al., 2005). The S1P measured by mass spectrometry of whole thymic tissue is largely inaccessible to $\mathrm{S} 1 \mathrm{P}$ receptors, consistent with S1P's role as an intracellular metabolic intermediate. Against the variability of our measurements of S1P in control thymus, we are unable to detect an increase in extracellular S1P that causes partial receptor internalization.

\section{LPP3 is required in radiation-resistant cells}

To determine which cell type requires LPP3 to maintain low thymic S1P, we began by generating BM chimeras.
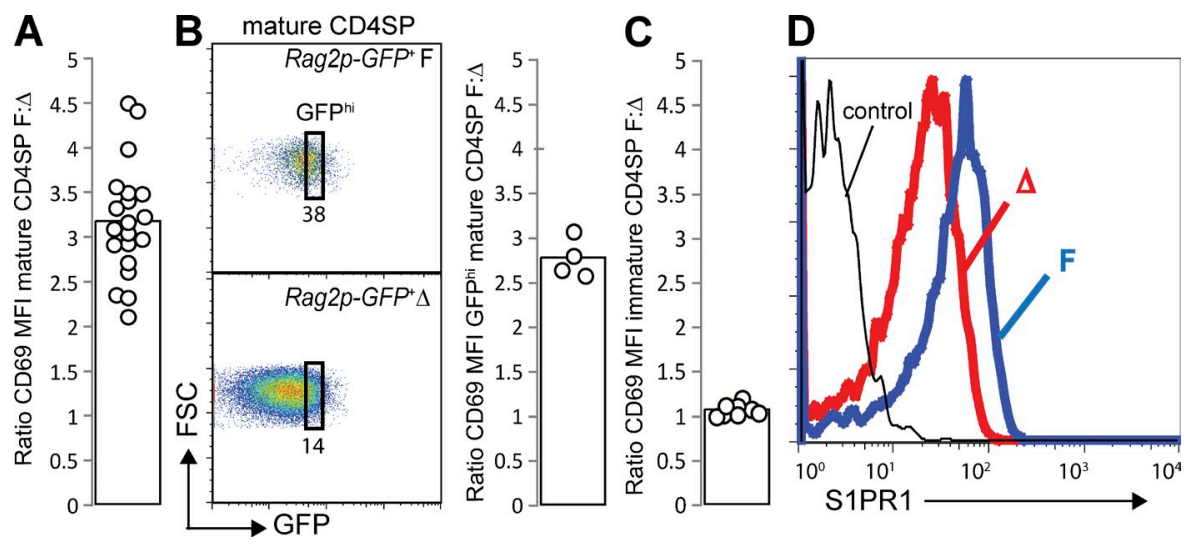

Figure 2. LPP3 deficiency causes downmodulation of CD69 and S1PR1. (A) The ratio of $\mathrm{CD} 69 \mathrm{MFI}$ of mature $\mathrm{CD} 4 \mathrm{SP}$ thymocytes from littermate controls (F)/CD69 MFI of mature CD4SP thymocytes from LPP3deficient mice $(\Delta)$. Each point represents one pair of mice, and the bar represents the mean. The graph compiles 13 experiments with a total of 21 pairs of mice. (B) Dot plots (left) show expression of GFP versus forward scatter (FSC) by mature CD4SP T cells from a representative Rag2p-GFP+ $L P P 3-$ deficient mouse $(\Delta)$ and Rag2p-GFP+ littermate control (F), and they indicate the GFPhi gate. The GFP MFI within the GFPhi gate differs by $<10 \%$ between littermate controls and LPP3-deficient

mice. The bar graph (right) shows the ratio of CD69 MFI of GFPhi mature CD4SP thymocytes from Rag2p-GFP+ littermate controls/CD69 MFI of GFPhi mature CD4SP thymocytes from Rag2p-GFP+ LPP3-deficient mice. Each point represents one pair of mice, and each bar represents the mean. The graph compiles data from four pairs of mice analyzed in two experiments. (C) The ratio of CD69 MFI of immature CD4SP thymocytes from littermate controls (F)/CD69 MFI of immature CD4SP thymocytes from LPP3-deficient mice $(\Delta)$. Each point represents one pair of mice, and each bar represents the mean. The graph compiles six experiments with a total of eight pairs of mice. (D) Surface S1PR1 levels on mature CD4SP thymocytes. The thin line shows staining with a control antibody. Data are representative of three pairs of mice analyzed in three experiments. 


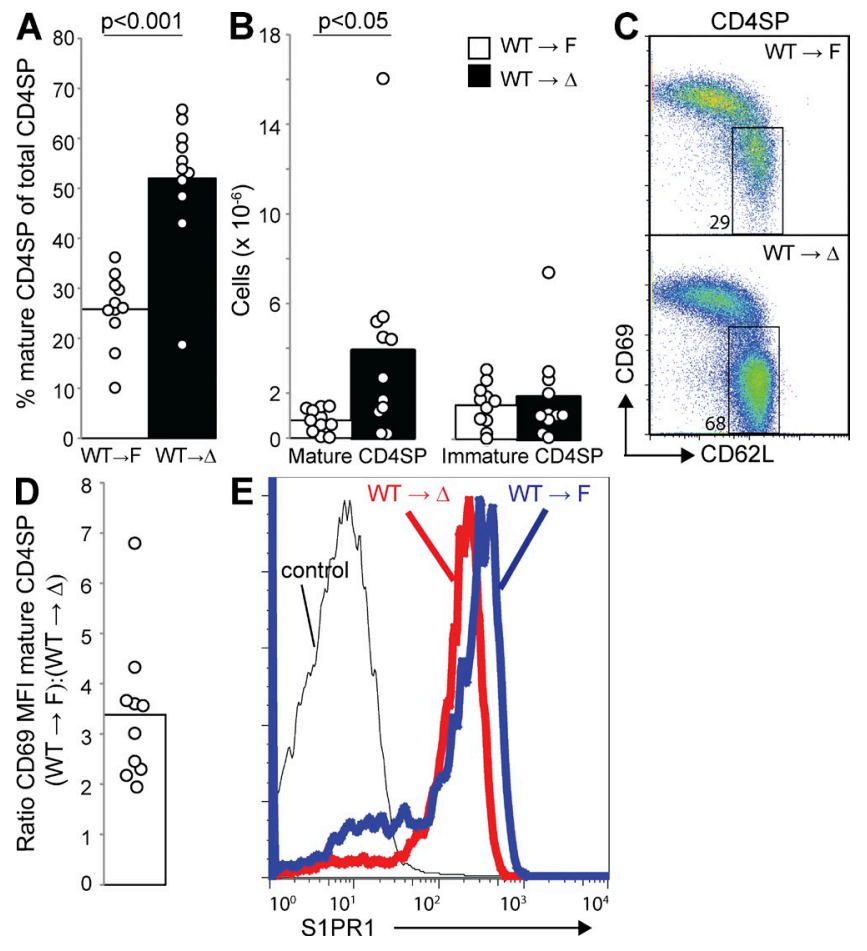

Figure 3. LPP3 is required in radiation-resistant cells to maintain low thymic S1P. CD45.2+ LPP3-deficient $(\Delta)$ mice and littermate controls (F) were lethally irradiated and reconstituted with CD45.1+ WT BM. The chimeras were analyzed 7-10 wk later. All analyses are gated on WT thymocytes (94-99\% of total). (A) Percentage of mature CD4SP thymocytes among total CD4SP thymocytes. (B) Total number of mature CD4SP thymocytes and immature CD4SP thymocytes. In $A$ and $B$, each point represents an individual mouse and bars show the mean. Graphs are a compilation of four experiments with a total of 10-11 mice per group. (C) Expression of CD69 and CD62L on CD4SP thymocytes. (D) The ratio of CD69 MFI of mature CD4SP thymocytes from littermate control chimeras/ CD69 MFI of mature CD4SP thymocytes from LPP3-deficient chimeras. Each point represents one pair of mice, and the bar represents the mean. The graph compiles 10 pairs of mice analyzed in four experiments.

(E) Surface S1PR1 expression on mature CD4SP thymocytes. The thin line shows staining with a control antibody. Data are representative of three pairs of mice analyzed in three experiments.

We observed no difference between lethally irradiated WT mice reconstituted with LPP3-deficient BM and mice reconstituted with littermate control BM (Fig. S3, A-E). However, when we compared lethally irradiated LPP3-deficient and littermate control mice reconstituted with WT BM, we found a striking difference. WT mature SP thymocytes in LPP3deficient animals have a fivefold accumulation (Fig. 3, A and B), a decrease in CD69 (Fig. 3, C and D), and a two- to threefold decrease in S1PR1 (Fig. 3 E). This suggests that LPP3 is required in radiation-resistant cells to maintain low thymic S1P. It is interesting to note that this pattern contrasts with that of S1P lyase, which is required in hematopoietic cells to maintain low lymphoid S1P (Schwab et al., 2005; lyase expression by stromal cells is likely also important). Treatment of LPP3deficient mice with the S1P lyase inhibitor deoxypyridoxine$\mathrm{HCl}$ further increases thymic S1P (Fig. S3 F).
LPP3 is expressed by multiple radiation-resistant cell types To determine which radiation-resistant cell type must express LPP3 to maintain low thymic S1P, we began by asking which cells express Ppap $2 b$ mRNA using quantitative PCR on sorted cells from WT mice. Consistent with the importance of LPP3 on radiation-resistant cells, we found that Ppap $2 b$ mRNA is enriched $100-$ fold in CD $45^{-}$thymic stroma compared with $\mathrm{T}$ cells. However, there are no dramatic differences in expression between $\mathrm{EpCAM}^{+}$epithelial cells, CD $31^{+}$endothelial cells, and other $\mathrm{CD}^{4} 5^{-}$stromal cells (Fig. 4 A). We also asked whether any of these cell types differ in expression of the other five S1P-degrading enzymes, suggesting that they might be uniquely dependent on LPP3. We found that LPP1 (Ppap2a) and LPP2 (Ppap2c) have a similar pattern to LPP3 (Fig. 4A) and that the S1P-specific enzymes S1P lyase (Spgl1), S1P phosphatase 1 (SPP1; Sgpp 1), and SPP2 (Sgpp2) are also expressed by all subsets of radiation-resistant cells (Fig. 4 B).

Our next attempt to narrow down the cell type that must express LPP3 was to ask whether Mx1-Cre deletes preferentially in any radiation-resistant cell types in the thymus. We crossed mice expressing Mx1-Cre with an enhanced (E) YFP reporter strain, R26R-EYFP, which has EYFP in the ubiquitously expressed Rosa 26 locus preceded by a floxed transcriptional stop (Srinivas et al., 2001), treated the pups with pI-pC at 3-5 d after birth, and analyzed the mice as adults. Analysis of disaggregated thymocytes by flow cytometry revealed deletion in approximately two thirds of epithelial cells, one third of endothelial cells, and $10 \%$ of other stroma, as well as $>90 \%$ of hematopoietic cells (Fig. 4 C). Because the strong YFP expression by lymphocytes obscured analysis of YFP expression by radiation-resistant cells using confocal microscopy, we also reconstituted lethally irradiated adults with WT BM. Analysis of thymic sections from the chimeras confirmed that Mx1Cre deletes in multiple radiation-resistant cell types, including epithelial cells and endothelial cells (Fig. 4 D).

Staining of frozen thymic sections with an antibody to LPP3 revealed robust protein expression by medullary epithelial cells, which was largely absent in LPP3-deficient mice (Fig. 4 E). LPP3 seemed to ring the endothelial wall of blood vessels, consistent with results showing that LPP3 localizes to the basolateral side of cultured MDCK cells (Jia et al., 2003). This staining was less frequent in LPP3-deficient mice (Fig. 4 E). LPP3 protein was also expressed by a range of other stromal cells, likely including pericytes (Fig. S4).

LPP3 is required in both endothelial cells and epithelial cells We then began a candidate approach to determine which cell type must express LPP3. Because we observed high expression of LPP3 by endothelial cells and partial deletion in endothelial cells by Mx1-Cre, and because endothelial cells sit at the border of the high S1P environment of the blood and the low S1P environment of the thymus, we considered the possibility that LPP3 was required in endothelial cells to maintain low thymic S1P. To delete LPP3 in vascular endothelial cells, we crossed Ppap $2 b^{f / f}$ mice with mice carrying Cre recombinase driven by the Tie 2 promoter (Kisanuki et al., 2001). 

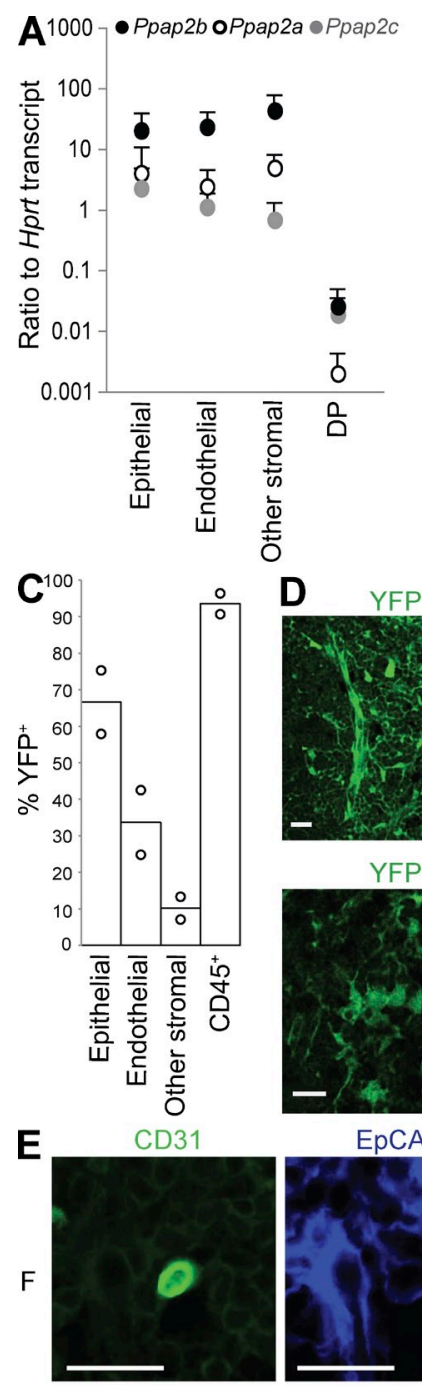

D
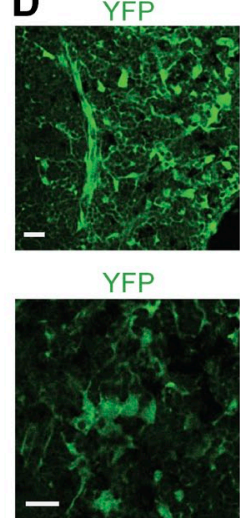

EpCAM
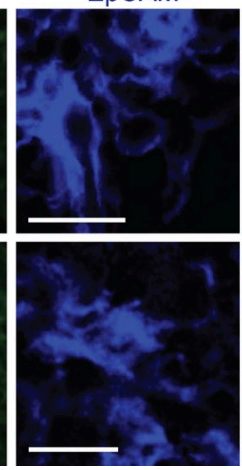
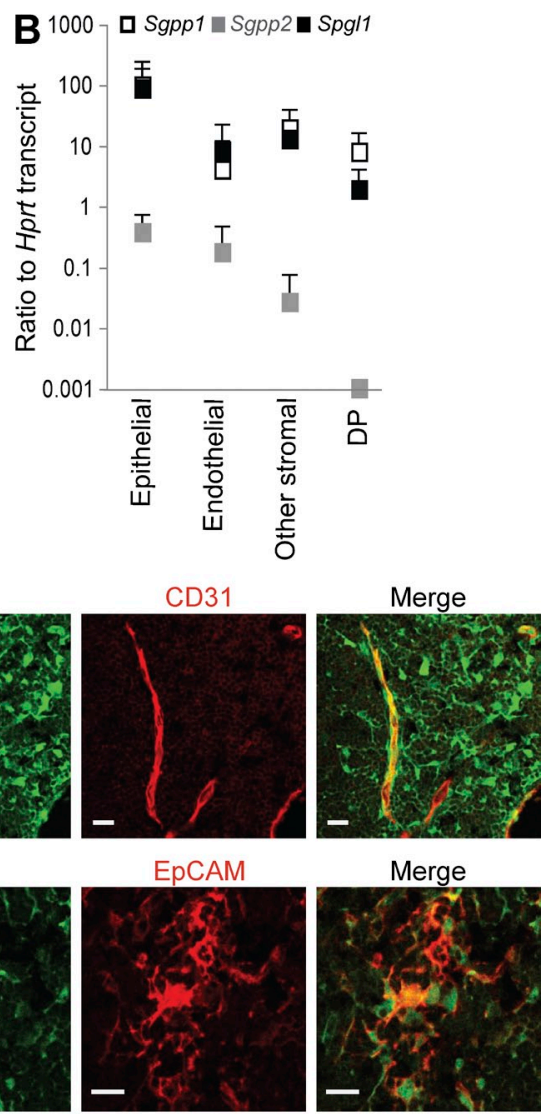

LPP3

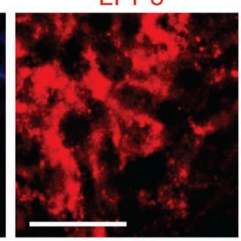

Merge
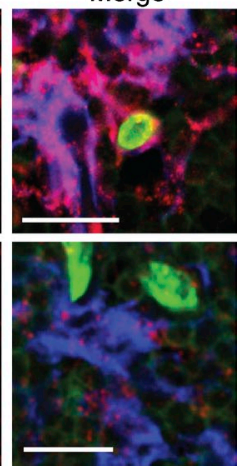

Figure 4. LPP3 is expressed by multiple radiation-resistant cell types. (A and B) Abundance of mRNA transcripts encoding the indicated S1P degrading enzymes, expressed relative to Hprt (hypoxanthine-guanine phosphoribosyltransferase) transcript, in sorted thymic populations, measured by quantitative RT-PCR. Ppap2a, LPP1; Ppap2b, LPP3; Ppap2c, LPP2; Sgpp1, SPP1; Sgpp2, SPP2; and Spgl1, S1P lyase. Endothelial cells were defined as CD45-CD31+, epithelial cells as CD45-EpCAM ${ }^{+}$,

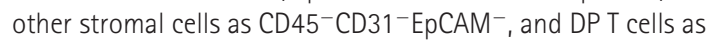
$\mathrm{CD}_{4}{ }^{+} \mathrm{CD} 8{ }^{+}$(none of the transcripts differ among DP, immature CD4SP, or mature CD4SP T cells, not depicted). The point shows the mean, and the vertical line shows the standard deviation. Data compile three to six experiments with mice on a B6 or a B6 $\times 129$ mixed background (the results did not differ by strain). Each experiment is a separate cell purification from three to four pooled mice, RNA extraction, and quantitative RT-PCR. (C) R26R-EYFP+ Mx1Cre+ mice were treated with pl-pC 3-5 $d$ after birth and analyzed at least 6 wk later. YFP expression by disaggregated thymic cell populations was measured by flow cytometry. CD $45^{+}$cells are primarily $T$ cells, as they were isolated by mechanical disruption. Each point represents an individual mouse, and bars show the mean. The graph compiles two mice analyzed in two experiments. (D) R26R-EYFP+ $\mathrm{M} \times 1 \mathrm{Cre}^{+}$mice were treated with $\mathrm{pl}-\mathrm{pC} 3-5 \mathrm{~d}$ after birth. Adults were lethally irradiated and reconstituted with WT BM. The resulting chimeras were analyzed 7-10 wk later. Frozen thymic sections were stained for CD31 to mark endothelial cells or EpCAM to mark epithelial cells and visualized by confocal microscopy. Bars, $20 \mu \mathrm{m}$. The image is representative of two mice analyzed in two experiments. (E) Frozen thymic sections from LPP3-deficient mice and littermate controls were stained for CD31 to mark endothelial cells, EpCAM to mark epithelial cells, and LPP3 and were visualized by confocal microscopy. Bars, $20 \mu \mathrm{m}$. The image is representative of two pairs of mice analyzed in two experiments.

periphery of these mice (Fig. S5 B). We observed a decrease of surface CD69 on mature T cells, which is, again, significant but less dramatic than in mice in which deletion was mediated by Mx1-Cre (Fig. 5, $\mathrm{C}$ and D; CD69 is higher in Ppap 2bf/- Cdh5(PAC)CreERT2 ${ }^{+}$than in Ppap $2 b^{f /-}$ or f/f $M x 1 \mathrm{Cre}^{+}$mice with $\mathrm{P}<0.01)$. Finally, we observed at most a slight

We had no live-born Ppap2 $b^{f f} \mathrm{Tie} 2-\mathrm{Cre}^{+}$pups (unpublished data), which was not surprising as Ppap $2 b^{-/-}$embryos suffer severe vascular defects (Escalante-Alcalde et al., 2003). To circumvent embryonic lethality, we used the inducible CreERT2 recombinase under the endothelialVE-Cadherin (Cdh5) promoter (Wang et al., 2010). We treated Ppap $2 b^{f-C}$ Cdh5(PAC)CreERT2 ${ }^{+}$mice, as well as littermate controls, with tamoxifen to induce excision.

We saw a twofold accumulation of mature $\mathrm{T}$ cells in Ppap 2bf-Cdh5(PAC)-CreERT2 $2^{+}$mice compared with littermate controls, which is significant but smaller than in mice in which deletion was mediated by Mx1-Cre (Fig. 5, A and B; the cell number in Ppap $2 b^{f-}$ Cdh5(PAC)-CreERT2 ${ }^{+}$mice is less than in Ppap $2 b^{f /-~ o r f / f ~} \mathrm{Mx} 1 \mathrm{Cre}^{+}$mice with $\mathrm{P}<0.01$ ). We saw a moderate reduction in the number of $\mathrm{T}$ cells in the down-modulation of S1PR1 on mature T cells (Fig. 5 E). We suspect that down-modulation is difficult to detect as a result of the relatively mild phenotype and limited sensitivity of our antibody.

To determine the pattern of deletion, we crossed mice expressing Cdh5(PAC)-CreERT2 with the YFP reporter strain. Confocal microscopy of thymic sections revealed specific deletion in endothelial cells (Fig. $5 \mathrm{~F}$ and Fig. S5 A), which was confirmed by analysis of disaggregated thymic cells by flow cytometry. We saw variable excision, ranging from 20 to $70 \%$, whereas deletion in other cell types was undetectable (Fig. 5 G). It is possible that the intermediate effect of LPP3 deletion within endothelial cells is a result of incomplete excision. It is also possible that the loss of LPP3 in endothelial cells causes a very small increase in thymic S1P but that 

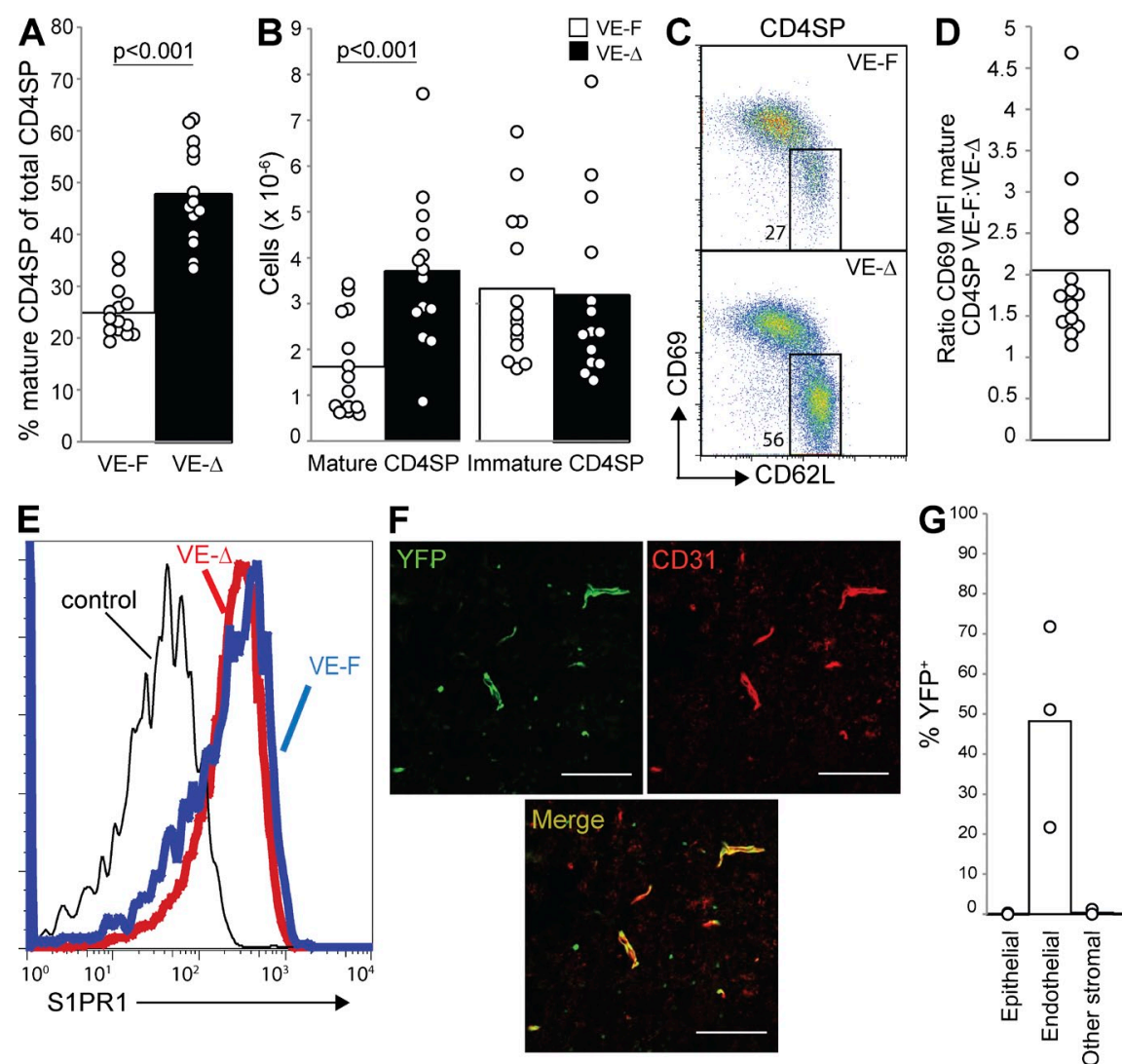

Figure 5. LPP3 expression by endothelial cells is required to maintain low thymic S1P. Mice in which LPP3 was deleted by VE-Cadherin-CreERT2 (VE- $\Delta_{i}$ Ppap2 $b^{f /-}$ Cdh5(PAC)-CreERT2+, treated with tamoxifen at 3-4 wk old) or littermate controls (VE-F; Ppap26 ${ }^{f /+}$ Cdh5(PAC)-CreERT2+, Ppap2b $b^{f /+}$, or Ppap2 $b^{f /}$, treated with tamoxifen at 3-4 wk old) were analyzed at least $4 \mathrm{wk}$ after tamoxifen treatment. (A) Percentage of mature CD4SP thymocytes among total CD4SP thymocytes. (B) Total number of mature CD4SP thymocytes and immature CD4SP thymocytes. In $A$ and $B$, each point represents an individual mouse and bars show the mean. Graphs are a compilation of 11 experiments with a total of 14 mice per group. (C) Expression of CD69 and CD62L on CD4SP thymocytes. (D) The ratio of CD69 MFI of mature CD4SP thymocytes from littermate controls/ CD69 MFI of mature CD4SP thymocytes from VE- $\Delta$ mice. Each point represents one pair of mice, and the bar represents the mean. The graph compiles 14 pairs of mice analyzed in 11 experiments. (E) Surface S1PR 1 expression on mature CD4SP thymocytes. The thin line shows staining with a control antibody. We saw slight down-modulation in two experiments and no detectable shift in a third. (F) Frozen thymic sections from tamoxifentreated $R 26 R-E Y F P^{+} C d h 5(P A C)-C r e E R T 2^{+}$mice were stained for CD31 to mark endothelial cells and visualized by confocal microscopy. Bars, $100 \mu \mathrm{m}$. The image is representative of two mice analyzed in two experiments. (G) YFP expression by disaggregated thymic cell populations from tamoxifen-treated R26R-EYFP+Cdh5(PAC)-CreERT2+ mice was measured by flow cytometry. CD $45^{+}$cells are primarily T cells, as they were isolated by mechanical disruption. Each point represents an individual mouse, and bars show the mean. The graph compiles three mice analyzed in three experiments.

the elevated $\mathrm{S} 1 \mathrm{P}$ is precisely where $\mathrm{T}$ cells most need a sharp gradient to egress as they cross the blood vessel wall into circulation.

Because we also observed high expression of LPP3 by thymic epithelial cells and efficient deletion in thymic epithelial cells by $\mathrm{Mx} 1-\mathrm{Cre}$, we considered the possibility that LPP3 was required in these cells. To delete LPP3 in epithelial cells, we used the Cre recombinase under the Keratin 14 promoter (Dassule et al., 2000). We bred Ppap2 $b^{f /-} \mathrm{Krt14}-\mathrm{Cre}^{+}$ mice. Littermate controls were Ppap $2 b^{f /+} \mathrm{Krt} 14 \mathrm{Cre}^{+}$, Ppap $2 b^{f /+}$, or Ppap $2 b^{f /-}$.

Mature T cells in the thymus of Ppap $2 b^{f /-} \mathrm{Krt} 14-\mathrm{Cre}^{+}$mice have a 3.5-fold accumulation (Fig. 6, A and B), accompanied by a small reduction of $\mathrm{T}$ cells in the periphery (Fig. S6 B). Mature T cells in the thymus of Ppap $2 b^{f /-} \mathrm{Krt}_{14-\mathrm{Cre}^{+}}$mice also display down-modulation of CD69 (Fig. 6, C and D) and a twofold decrease in S1PR1 compared with littermate controls (Fig. 6 E).

To determine the pattern of deletion, we crossed mice expressing Keratin 14-Cre with the YFP reporter strain. In both the LPP3 and YFP reporter crosses, Cre recombinase was carried only by the father to avoid potential widespread deletion as a result of expression in the oocyte (Hafner et al., 2004).
Confocal microscopy of thymic sections revealed deletion primarily in medullary epithelial cells (Fig. 6 F, Fig. S6 A). This pattern was also seen in analysis of disaggregated thymic cells by flow cytometry. We observed excision within $\sim 75 \%$ of $\mathrm{EpCAM}^{+}$cells (Fig. $6 \mathrm{G}$ ). We have confirmed a requirement for LPP3 in epithelial cells using Ppap $2 b^{f /-}$ Foxn1-Cre ${ }^{+}$mice (Fig. S6, C and D); FoxN1-Cre deletes specifically and universally in thymic epithelial cells (Gordon et al., 2007).

\section{DISCUSSION}

We found that LPP3 is essential to enable efficient thymic egress, and several lines of evidence suggest that LPP3 promotes exit by maintaining low thymic S1P. In the absence of biochemical evidence of increased S1P, uncertainty remains in the interpretation of our results; measurements of total thymic S1P by mass spectrometry are uninformative because the background of intracellular S1P (500 nM), combined with measurement variability, is too high to detect an increase in extracellular S1P predicted to cause partial S1PR1 downmodulation ( $<10 \mathrm{nM}$ or $2 \%$ of total). Nonetheless, because S1P is the only LPP3 substrate that has been implicated in egress, CD69 down-modulation, or S1PR1 internalization, 

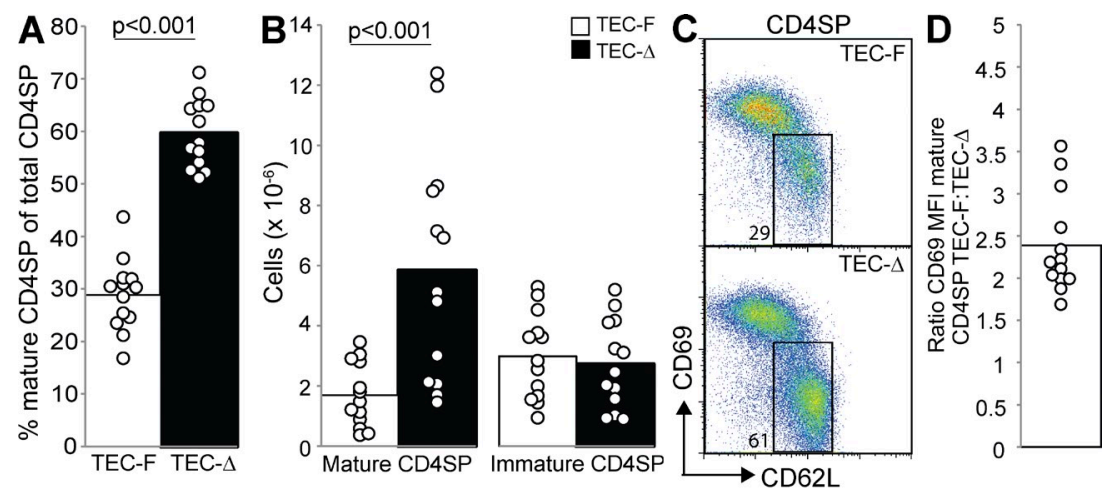

E

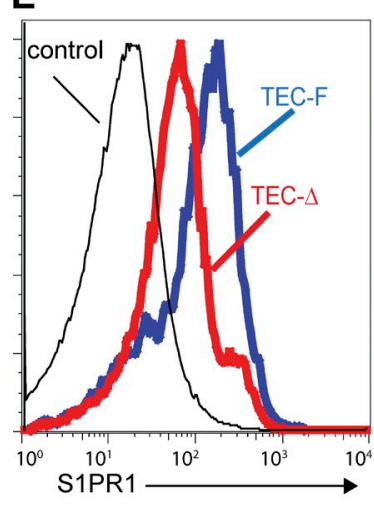

$\mathbf{F}$
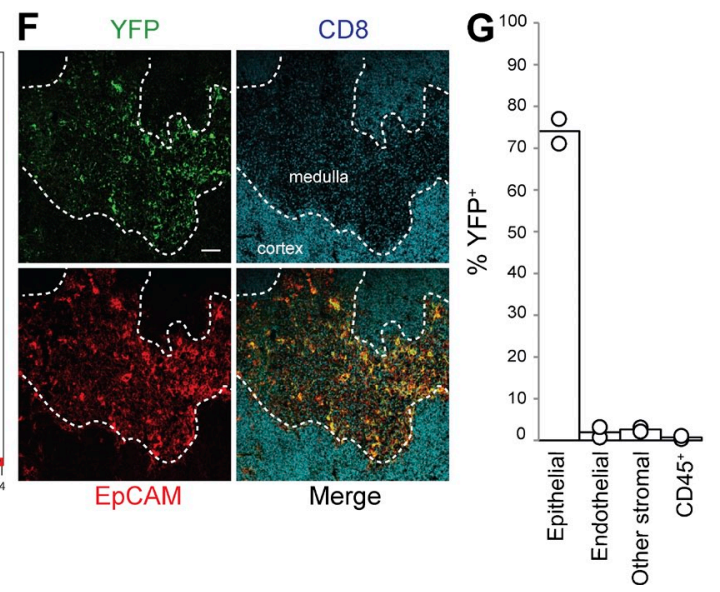

the simplest interpretation of our data is that LPP3 is functioning to limit thymic S1P.

This is the first time to our knowledge that a phosphatase has been implicated in lymphoid organ S1P regulation in vivo. The Drosophila melanogaster homologues of LPP3, wunen and wunen 2 , are required to guide germ cell migration in the developing embryo. Germ cells and the surrounding tissue compete for hydrolysis of a lipid phosphate, although the identity of this lipid is unknown (Renault and Lehmann, 2006). Ppap $2 b^{-/-}$mice die at or before embryonic day 10.5 with failure to form a chorioallantoic placenta and yolk sac vasculature (Escalante-Alcalde et al., 2003). It is not known whether this phenotype is the result of an imbalance in phospholipids and, if so, which phospholipid, or whether it is the result of a phosphatase-independent function of LPP3 (Humtsoe et al., 2003). Ppap $2 b^{f / f} \mathrm{Nestin}-\mathrm{Cre}^{+}$ mice have increased S1P in the cerebellum (López-Juárez et al., 2011). LPP3 is needed on both endothelial and epithelial cells, revealing a novel role of epithelial cells in enabling thymic egress.

We further found that although LPP1 and LPP2 have a similar expression pattern to LPP3, and S1P lyase and SPP1 are widely expressed in the thymus, they cannot compensate for the loss of LPP3. Moreover, deletion of LPP3 in either epithelial cells or endothelial cells is sufficient to cause an increase in thymic S1P and an egress block. These observations suggest that $\mathrm{S} 1 \mathrm{P}$ generation and destruction are finely balanced. Little is known about LPP3 regulation, although
Figure 6. LPP3 expression by epithelial cells is required to maintain low thymic S1P. Mice in which LPP3 was deleted by Keratin 14-Cre (TEC- $\Delta_{i}$; Ppap2 $b^{f /-}$ Krt14Cret) or littermate controls (TEC-F; Ppap2 $b^{f /+} \mathrm{Krt14Cre}^{+}$, Ppap2 $\mathrm{b}^{f /+}$, or Ppap2 $\mathrm{b}^{f /-}$ ) were analyzed at 6 wk or older. (A) Percentage of mature CD4SP thymocytes among total CD4SP thymocytes. (B) Total number of mature CD4SP thymocytes and immature CD4SP thymocytes. In A and B, each point represents an individual mouse and bars show the mean. Graphs compile 11 experiments with a total of 13 mice per group. (C) Expression of CD69 and CD62L on CD4SP thymocytes. (D) The ratio of CD69 MFI of mature CD4SP thymocytes from littermate controls/CD69 MFI of mature CD4SP thymocytes from TEC- $\Delta$ mice. Each point represents one pair of mice and the bar represents the mean. The graph compiles 13 pairs of mice analyzed in 11 experiments. (E) Surface S1PR1 expression on mature CD4SP thymocytes. Thin line shows staining with a control antibody. Data are representative of three pairs of mice analyzed in three experiments. (F) Frozen thymic sections from R26R-EYFP+Krt14Cre+ mice were stained for EpCAM to mark epithelial cells and CD8 to distinguish the cortex from the medulla and visualized by confocal microscopy. Bar, $100 \mu \mathrm{m}$. Image is representative of two mice in two experiments. (G) YFP expression by disaggregated thymic cell populations from R26R-EYFP+ $\mathrm{Krt14Cre}^{+}$mice was measured by flow cytometry. CD $45^{+}$cells are primarily $T$ cells, as they were isolated by mechanical disruption. Each point represents an individual mouse and bars show the mean. The graph compiles two mice analyzed in two experiments.

sion by endothelial cell lines is increased upon exposure to stimuli includingVEGF and TNF (Humtsoe et al., 2003; Wary and Humtsoe, 2005; Senda et al., 2009), and LPP3 expression by epithelial lines is increased upon exposure to stimuli including EGF (Kai et al., 1997; Humtsoe et al., 2003). We propose that S1P levels could be rapidly increased in response to physiological signals, not only by increasing phosphorylation of sphingosine but also simply by inhibiting degradation. This may be one reason that a ubiquitous lipid evolved to be a signaling molecule.

One question raised by these findings is what is the normal spatial distribution of S1P within the thymus and how is it altered in the absence of LPP3? On average, extracellular $\mathrm{S} 1 \mathrm{P}$ is lower in the thymus than in circulation (Schwab and Cyster, 2007), but whether there are local variations remains unknown. For example, whether a gradient of S1P guides $\mathrm{T}$ cells toward egress structures or whether $\mathrm{T}$ cells encounter S1P only as they probe the blood vessels is an open question. We hypothesize that in the absence of LPP3 in epithelial cells, which form a network throughout the thymus, S1P increases widely in the tissue, masking local S1P gradients and desensitizing $T$ cells to remaining egress cues. In the absence of LPP3 in endothelial cells, S1P may increase only proximal to blood vessels. Although the loss of LPP3 in endothelial cells has a 
minimal effect on average $\mathrm{T}$ cell S1PR 1, it may desensitize $\mathrm{T}$ cells to S1P just where they most need a sharp gradient to cross into circulation. LPP3 is also expressed by other stromal cells, likely including pericytes. Whether S1P is regulated differently in the thymic parenchyma, at the border with blood, and in the perivascular space warrants further investigation.

A second, related, question raised by these findings is what is the source of S1P that LPP3 destroys? LPP3 may be responsible for destroying excess S1P made intracellularly during membrane sphingolipid metabolism and secreted at some rate. LPP3 may also prevent plasma S1P from entering tissues. Vascular endothelial cells sit at the boundary of the high S1P environment of the blood and the low S1P environment of the tissue, and endothelial LPP3 may prevent S1P from crossing the blood vessel wall. Hematopoietic cells, particularly erythrocytes, are the major source of plasma S1P, but endothelial cells themselves may also contribute (Pappu et al., 2007; Hla et al., 2008; Venkataraman et al., 2008). Blood vessel endothelial cells efficiently secrete S1P in culture (Venkataraman et al., 2008), and lymphatic endothelial cells are the main source of lymph S1P (Pham et al., 2010). Intriguingly, LPP3 has been shown to localize to the basolateral side of cultured MDCK cells (Jia et al., 2003), and our LPP3 antibody stain seems to ring blood vessels. The subcellular organization of S1P metabolic enzymes may enable vascular endothelial cells to play a dual role in S1P generation and destruction. Thymic vessels are unique in that they have a double-walled structure with vascular endothelial cells surrounded by epithelial cells (Ushiki, 1986; Kato, 1997; Ushiki and Takeda, 1997; Mori et al., 2007), so a requirement for LPP3 in epithelial cells is also consistent with a role in destroying plasma S1P.

Although our original hypothesis was that LPP3 is destroying metabolic or plasma S1P, it is also possible that LPP3 is responsible for preventing the spread of S1P made and secreted for a highly localized signaling. Like vascular endothelial cells, epithelial cells express high levels of the S1P generating enzyme sphingosine kinase 1 (unpublished data). A role for S1P production by thymic epithelial cells has not been shown, although many are plausible. Epithelial cell S1P secretion may facilitate $T$ cell egress, leading them across the first basement membrane of the double-walled vessels. This would be analogous to the role of pericytes, which sit in the perivascular space and whose S1P secretion promotes exit (Zachariah and Cyster, 2010). Epithelial cell S1P may affect T cell motility or shape T cell maturation; T cell S1PR 1 has been shown to inhibit development of regulatory T cells (Liu et al., 2009), but the source of S1P within the thymus has not been identified. Finally, it is tempting to speculate that S1P may play a more general role in epithelial cell junctions, analogous to its role in endothelial barrier function. In this regard, it is interesting to note that LPP3 was first cloned in an attempt to identify genes required for intestinal epithelial cell differentiation (Barilà et al., 1996). Currently there are no techniques to measure changes in extracellular S1P in nonlymphoid tissues, but LPP3 may play a role in regulating not only thymic S1P but also S1P in heavily epithelial tissues, such as the lung, small intestine, and skin and may be an attractive target to manipulate S1P selectively in these organs. The observation that S1P levels are very tightly regulated offers the hope that highly specific drugs can be developed to manipulate S1P signaling, lymphocyte trafficking, and inflammation.

\section{MATERIALS AND METHODS}

Mice. Ppap 2bfff (Escalante-Alcalde et al., 2007), R26R-EYFP (Srinivas et al., 2001), Rag2p-GFP (Yu et al., 1999), Mx1-Cre (Kühn et al., 1995), Keratin 14-Cre (Dassule et al., 2000), FoxN1-Cre (Gordon et al., 2007), Tie2-Cre (Kisanuki et al., 2001), and Cdh5(PAC)-CreERT2 (Wang et al., 2010) mice have been previously described. CD 45.2 $2^{+} \mathrm{B} 6$ and $\mathrm{CD} 45.1^{+}$congenic B6 mice were obtained from the National Cancer Institute.

To induce deletion by $\mathrm{Mx} 1-\mathrm{Cre}, 3-5-\mathrm{d}$-old mice received a single intraperitoneal injection with 50-100 $\mu \mathrm{l} \mathrm{pI-pC} \mathrm{(Midland} \mathrm{Scientific)} \mathrm{at} \mathrm{a} \mathrm{concen-}$ tration of $10 \mathrm{mg} / \mathrm{ml}$ in sterile PBS. To induce deletion by VE-Cadherin CreERT2, 3-4-wk-old mice received three intraperitoneal injections on three consecutive days with $50 \mu \mathrm{l}$ tamoxifen (Sigma Aldrich) at a concentration of $20 \mathrm{mg} / \mathrm{ml}$ in maize oil.

Mice were housed in specific pathogen-free conditions at the Skirball Institute animal facility. All animal experiments were performed in accordance with protocols approved by the New York University Institutional Animal Care and Use Committee.

BM chimeras, BrdU labeling, intrathymic injection, and deoxypyridoxine treatment. For BM chimeras, recipients were lethally irradiated by two 6.5 Gray doses of $\gamma$ irradiation from a cesium source separated by $3 \mathrm{~h}$ and received 2-10 $\times 10^{6} \mathrm{BM}$ cells by intravenous injection. Chimeras were analyzed at least $7 \mathrm{wk}$ after transplantation. For BrdU labeling, $0.8 \mathrm{mg} / \mathrm{ml}$ of BrdU (Sigma-Aldrich) was added to the drinking water and changed daily.

For intrathymic injection, mice were anesthetized with $4 \%$ isoflurane in medical air and maintained under anesthesia using a nose cone with $1.5 \%$ isoflurane in medical air. Hair was removed from the thorax using depilatory cream, and animals were placed on a heat pad for the injection. Thymus visualization was performed in real time using a $30-\mathrm{MHz} 707 \mathrm{~B}$ ultrasound probe (VisualSonics). The injection needle (Hamilton syringe with 30-gauge needle) was mounted on a 3D micromanipulator and the tip of the needle placed in the imaging plane. $20 \mu \mathrm{l}(10 \mu \mathrm{l}$ in each lobe) sulfo-NHS biotin (Thermo Fisher Scientific) at a concentration of $5 \mathrm{mg} / \mathrm{ml}$ in PBS was injected. For 4-deoxypyridoxine-HCl (DOP) treatment, $30 \mathrm{mg} /$ liter DOP (Sigma-Aldrich) and $10 \mathrm{~g} /$ liter sucrose (to overcome taste aversion) were added to the drinking water. Control mice received drinking water with $10 \mathrm{~g} /$ liter sucrose.

Cell preparation. Lymphocytes were isolated by mechanical disruption and filtration through a 70- $\mu \mathrm{m}$ cell strainer and enumerated with a cell counter (Z1 Particle Counter; Beckman Coulter) set to detect nuclei between 3.5 and $7 \mu \mathrm{m}$. Thymic stromal cells were isolated as previously described (Gray et al., 2002). In brief, the thymus was diced into small pieces and rotated for $30 \mathrm{~min}$ at $4^{\circ} \mathrm{C}$ in RPMI 1640 supplemented with $10 \mathrm{mM}$ Hepes (RPMI/H). The supernatant containing lymphocytes was removed, the remaining fragments were briefly agitated in ice cold RPMI/H, the supernatant containing lymphocytes was removed, the fragments were briefly agitated once more in ice-cold $\mathrm{RPMI} / \mathrm{H}$, and the supernatant containing lymphocytes was removed. The remaining fragments were subjected to three successive digestions for $15 \mathrm{~min}$ at $37^{\circ} \mathrm{C}$ in $\mathrm{RPMI} / \mathrm{H}$ containing Blendzyme III (Roche) at $0.14 \mathrm{U} / \mathrm{ml}$ and DNase I at $1 \mathrm{mg} / \mathrm{ml}$. In the middle and at the end of the first digestion, the fragments were disaggregated with a Pasteur pipette and the supernatant was discarded. In the middle and at the end of the second digestion, the fragments were disaggregated with a 22-gauge needle. In the middle and at the end of the third digestion, the fragments were disaggregated with a 26 -gauge needle. The supernatants from the final two digestions and remaining fragments were pooled and incubated for $10 \mathrm{~min}$ on ice in PBS 1\% FBS $5 \mathrm{mM}$ EDTA to yield a mixture enriched in stromal cells. Cells were stained and analyzed using a FACSCalibur (BD) or LSRII (BD) or sorted using a MoFlo (Beckman Coulter) or FACSAria (BD). Data were analyzed using Flowjo (v. 8.8.1; Tree Star). 
Quantitative RT-PCR. Total RNA was extracted from sorted cell populations using TRIZOL (Invitrogen) according to the manufacturer's instructions. Before RT, RNA was treated with DNase I (Invitrogen). The RNA was converted to cDNA with the Superscript III First Strand Synthesis System (Invitrogen) or the USB First-Strand cDNA Synthesis kit (Affymetrix) according to the manufacturer's instructions, using a mix of oligo dT and random hexamers as primers. Real-time quantitative PCR was performed on an iCycler using iQ SYBR Green Supermix (Bio-Rad Laboratories) according to the manufacturer's instructions. To control for DNA contamination, primers were designed to span a large intron when possible, and a reaction without reverse transcription was performed in parallel for each sample/primer pair. To control for nonspecific amplification, the size of the reaction products was analyzed by agarose gel electrophoresis. All primer pairs were tested for linear amplification over two orders of magnitude. Primers used were the following: Hprt sense, $5^{\prime}$-AGGTTGCAAGCTTGCTGGT-3'; Hprt antisense, 5'-TGAAGTACTCATTATAGTCAAGGGCA-3'; S1pr1 sense, 5'-AGACCCAGAGTCCTG-3'; S1pr1 antisense, 5'-GCGAGCAATCCAATG-3'; Ppap $2 b$ sense, 5'-GGTGGCCTGCTGCATAGTGTT-3'; Ppap $2 b$ antisense, 5'-TCCTGTCGATGATGTCCACGGG-3'; Ppap $2 a$ sense, 5'-CATACTGGGGCTTGGCTT-3'; Ppap $2 a$ antisense, 5'-TCCGACGGCTTTGTAAAT-3'; Ppap $2 c$ sense, 5' -CCGGCTCTGCTGGAAGTGGG-3'; Ppap $2 c$ antisense, 5'-GCGGACCGTGAGGCAGGC-3'; Sgpp 1 sense, 5'-GGCGCATATTTGTAAGTTTGG-3'; Sgpp 1 antisense, 5'-TTCTATCCTGGATGTCATTGCT-3'; Sgpp 2 sense, 5' -TGTCTCAGCAGACTCTACAC-3'; Sgpp 2 antisense, 5'-GAGTCCAGGGAATCGATGAG-3'; Spgl1 sense, 5'-TATTGCACCAAATATGAGCC-3'; and Spgl1 antisense, 5'-CTGTTGTTCGATCTTACGTC-3'.

Antibodies. S1PR1-specific antibody and control were previously described (Lo et al., 2005). Some stainings were done with a second batch of antiserum made in the same way and tested for specificity. In this case, a polyclonal rabbit anti-GST antibody (Bethyl Laboratories, Inc.) was used as a control. LPP3-specific antibody and staining technique were previously described (López-Juárez et al., 2011).

Fluorochrome- or biotin-conjugated anti-CCR7 (clone 4B12), CD4 (clone RMA4-5 or GK1.5), CD8 (clone 53-6.7), CD19 (clone 6D5), CD31 (clone MEC13.3 for immunohistology, clone 390 for flow cytometry), CD44 (clone IM7), CD45 (clone 30F11), CD45.1 (clone A20), CD45.2 (clone 104), CD62L (clone MEL14), CD69 (clone H1.2F3), CXCR4 (clone 2B11), EpCAM (clone G8.8), NK1.1 (clone PK136), CD25 (clone PC61), and TCR- $\gamma \delta$ (clone GL3) were purchased from BioLegend, eBioscience, or BD Biotin-conjugated polyclonal anti-PDGFR- $\beta$ was purchased from R\&D Systems. Intracellular staining for BrdU was done using the BD FITC BrdU Flow kit according to the manufacturer's instructions.

Flow cytometry and confocal imaging. Flow cytometry was done using standard conditions. All staining was performed on ice, except for CCR7 staining which was at $37^{\circ} \mathrm{C}$. Staining for S1PR1 was done with $0.05 \%$ sodium azide in all buffers.

Confocal imaging was done using standard conditions. In brief, the thymus was excised, fixed overnight at $4^{\circ} \mathrm{C}$ in periodate-lysine-paraformaldehyde medium (PLP; 0.05 M phosphate buffer, $\mathrm{pH}$ 7.4,0.1 M L-Lysine, $10 \mathrm{mg} / \mathrm{ml}$ paraformaldehyde, and $2 \mathrm{mg} / \mathrm{ml} \mathrm{NaIO}$ ) and progressively dehydrated at $4{ }^{\circ} \mathrm{C}$ in sucrose $(10,20$, and $30 \%$ in PBS). Tissues were snap frozen in OCT compound (Tissue-Tek; Sakura). 10- $\mu \mathrm{m}$-thick tissue sections were rehydrated (rehydration and staining buffer was PBS with $4 \%$ mouse serum, $4 \%$ rat serum, $1 \%$ Triton X-100, and $0.1 \mathrm{M}$ Tris), stained, and imaged using a confocal microscope (LSM510; Carl Zeiss) with a $40 \times$ oil immersion objective. Images were processed using ImageJ software (version 1.41; National Institutes of Health).

Mass spectrometry. Before taking thymus, mice were perfused with $10 \mathrm{ml}$ PBS. Samples were snap frozen in liquid nitrogen and stored at $-80^{\circ} \mathrm{C}$. Lipids were purified and mass spectrometry was performed as previously described (López-Juárez et al., 2011).
Online supplemental material. Fig. S1 shows the effect of LPP3 deletion on the numbers of DN and DP T cells in the thymus, that LPP3 deletion is associated with reduced numbers of CD4 T cells in LNs and spleen, and that LPP3 deletion inhibits egress of mature CD8 T cells from the thymus. Fig. S2 shows that LPP3 deletion does not detectably alter S1pr1 transcript in mature thymocytes or surface CCR7 expression on mature thymocytes, and that an increase in total thymic S1P is not detectable by mass spectrometry. Fig. S3 shows that chimeras generated with LPP3-deficient BM do not have elevated thymic S1P and that inhibition of S1P lyase further increases thymic S1P in LPP3-deficient mice. Fig. S4 shows expression of LPP3 and the pericyte marker PDGFR- $\beta$ by confocal microscopy. Fig. S5 shows specificity of deletion by Cdh5(PAC)-CreERT2 and a reduction in the number of T cells in the periphery of Ppap $2 b^{f /-} C d h 5(P A C)-C r e E R T 2^{+}$mice. Fig. S6 shows specificity of deletion by Krt14-Cre, a reduction in the number of $\mathrm{T}$ cells in the periphery of Ppap $2 b^{f-} \mathrm{Krt} 14-\mathrm{Cre}^{+}$mice, and an accumulation of mature T cells in the thymus of Ppap $2 b^{f /-}$ Foxn $1 \mathrm{Cre}^{+}$mice. Online supplemental material is available at http://www.jem.org/cgi/content/full/jem.20102551/DC1.

We are grateful to Susan Smyth for rederived Ppap2 $b^{f f}$ mice and to Andrew Farr and Nancy Manley for FoxN1-Cre+ mice. We thank Dan Littman, Mike Dustin, Ruth Lehmann, David Roth, and Nilabh Shastri for valuable discussions and Jason Cyster, MacLean Sellars, Phillipe Bousso, Marc Bajenoff, Jelena Nedjic, and Lauren Pitt for insightful comments on the manuscript.

This work was supported by a Cancer Research Institute Investigator Award and National Institutes of Health (NIH) grant 1R01AI085166-01A1 to S.R. Schwab, $\mathrm{NIH}$ grants R01GM50388 and P20RR021954 to A.J. Morris, a Human Frontier Science Program Long-Term Fellowship to B. Bréart, NIH training grant T32HD007520 to A. Mendoza, and an American Heart Association Great Rivers Affiliate Predoctoral Fellowship to A.K. Salous. This work used facilities in the New York University (NYU) Flow Cytometry Core, directed by Peter Lopez and partially supported by NIH/NCI 5 P30CA16087-31; the NYU Transgenic Core, directed by Mary Jean Sunshine and partially supported by NIH/NCl 5 P30CA16087-31; and the NYU Microscopy Core, directed by Alice Liang.

The authors have no conflicting financial interests.

Submitted: 8 December 2010

Accepted: 15 April 2011

\section{REFERENCES}

Alfonso, C., M.G. McHeyzer-Williams, and H. Rosen. 2006. CD69 downmodulation and inhibition of thymic egress by short- and long-term selective chemical agonism of sphingosine 1-phosphate receptors. Eur.J. Immunol. 36:149-159. doi:10.1002/eji.200535127

Allende, M.L., J.L. Dreier, S. Mandala, and R.L. Proia. 2004. Expression of the sphingosine 1-phosphate receptor, S1P1, on T-cells controls thymic emigration. J. Biol. Chem. 279:15396-15401. doi:10.1074/jbc .M314291200

Alvarez, S.E., K.B. Harikumar, N.C. Hait, J. Allegood, G.M. Strub, E.Y. Kim, M. Maceyka, H. Jiang, C. Luo, T. Kordula, et al. 2010. Sphingosine-1phosphate is a missing cofactor for the E3 ubiquitin ligase TRAF2. Nature. 465:1084-1088. doi:10.1038/nature09128

Barilà, D., M. Plateroti, F. Nobili, A.O. Muda, Y. Xie, T. Morimoto, and G. Perozzi. 1996.The Dri 42 gene, whose expression is up-regulated during epithelial differentiation, encodes a novel endoplasmic reticulum resident transmembrane protein. J. Biol. Chem. 271:29928-29936. doi:10.1074/ jbc.271.47.29928

Blair-Handon, R., K. Mueller, and S. Hoogstraten-Miller. 2010. An alternative method for intrathymic injections in mice. Lab Anim. (NY). 39:248252. doi:10.1038/laban0810-248

Boursalian, T.E., J. Golob, D.M. Soper, C.J. Cooper, and P.J. Fink. 2004 Continued maturation of thymic emigrants in the periphery. Nat. Immunol. 5:418-425. doi:10.1038/ni1049

Brindley, D.N., J. Xu, R. Jasinska, and D.W. Waggoner. 2000. Analysis of ceramide 1-phosphate and sphingosine-1-phosphate phosphatase activities. Methods Enzymol. 311:233-244. doi:10.1016/S0076-6879(00)11086-9

Brinkmann,V., A. Billich, T. Baumruker, P. Heining, R. Schmouder, G. Francis, S. Aradhye, and P. Burtin. 2010. Fingolimod (FTY720): discovery and 
development of an oral drug to treat multiple sclerosis. Nat. Rev. Drug Discov. 9:883-897. doi:10.1038/nrd3248

Camerer, E., J.B. Regard, I. Cornelissen,Y. Srinivasan, D.N. Duong, D. Palmer, T.H. Pham, J.S. Wong, R. Pappu, and S.R. Coughlin. 2009. Sphingosine1-phosphate in the plasma compartment regulates basal and inflammation-induced vascular leak in mice. J. Clin. Invest. 119:1871-1879.

Carroll, W.M. 2010. Oral therapy for multiple sclerosis-sea change or incremental step? N. Engl. J. Med. 362:456-458. doi:10.1056/ NEJMe0912019

Dassule, H.R., P. Lewis, M. Bei, R. Maas, and A.P. McMahon. 2000. Sonic hedgehog regulates growth and morphogenesis of the tooth. Development. 127:4775-4785

Egerton, M., R. Scollay, and K. Shortman. 1990. Kinetics of mature T-cell development in the thymus. Proc. Natl.Acad. Sci.USA.87:2579-2582. doi:10 $.1073 /$ pnas.87.7.2579

Escalante-Alcalde, D., L. Hernandez, H. Le Stunff, R. Maeda, H.S. Lee, Jr-Gang-Cheng, V.A. Sciorra, I. Daar, S. Spiegel, A.J. Morris, and C.L. Stewart. 2003. The lipid phosphatase LPP3 regulates extra-embryonic vasculogenesis and axis patterning. Development. 130:4623-4637. doi:10 $.1242 / \mathrm{dev} .00635$

Escalante-Alcalde, D., R. Sánchez-Sánchez, and C.L. Stewart. 2007. Generation of a conditional Ppap2b/Lpp3 null allele. Genesis. 45:465-469. doi:10.1002/dvg.20314

Gordon, J., S. Xiao, B. Hughes III, D.M. Su, S.P. Navarre, B.G. Condie, and N.R. Manley. 2007. Specific expression of lacZ and cre recombinase in fetal thymic epithelial cells by multiplex gene targeting at the Foxn1 locus. BMC Dev. Biol. 7:69. doi:10.1186/1471-213X-7-69

Gray, D.H., A.P. Chidgey, and R.L. Boyd. 2002. Analysis of thymic stromal cell populations using flow cytometry. J. Immunol. Methods. 260:15-28. doi:10.1016/S0022-1759(01)00493-8

Hafner, M., J. Wenk, A. Nenci, M. Pasparakis, K. Scharffetter-Kochanek, N. Smyth, T. Peters, D. Kess, O. Holtkötter, P. Shephard, et al. 2004. Keratin 14 Cre transgenic mice authenticate keratin 14 as an oocyte-expressed protein. Genesis. 38:176-181. doi:10.1002/gene.20016

Hait, N.C., J.Allegood, M. Maceyka, G.M. Strub, K.B. Harikumar, S.K. Singh, C. Luo, R. Marmorstein, T. Kordula, S. Milstien, and S. Spiegel. 2009 Regulation of histone acetylation in the nucleus by sphingosine-1phosphate. Science. 325:1254-1257. doi:10.1126/science.1176709

Hannun, Y.A., and L.M. Obeid. 2008. Principles of bioactive lipid signalling: lessons from sphingolipids. Nat. Rev. Mol. Cell Biol. 9:139-150. doi: $10.1038 / \mathrm{nrm} 2329$

Hla, T. 2004. Physiological and pathological actions of sphingosine 1phosphate. Semin. Cell Dev. Biol. 15:513-520. doi:10.1016/j.semcdb .2004 .05 .002

Hla, T., K. Venkataraman, and J. Michaud. 2008. The vascular S1P gradient-cellular sources and biological significance. Biochim. Biophys. Acta. 1781:477-482.

Humtsoe, J.O., S. Feng, G.D. Thakker, J.Yang, J. Hong, and K.K. Wary. 2003. Regulation of cell-cell interactions by phosphatidic acid phosphatase 2b/VCIP. EMBO J. 22:1539-1554. doi:10.1093/emboj/cdg165

Jia, Y.J., M. Kai, I. Wada, F. Sakane, and H. Kanoh. 2003. Differential localization of lipid phosphate phosphatases 1 and 3 to cell surface subdomains in polarized MDCK cells. FEBS Lett. 552:240-246. doi:10.1016/ S0014-5793(03)00931-1

Kai, M., I. Wada, S. Imai, F. Sakane, and H. Kanoh. 1997. Cloning and characterization of two human isozymes of $\mathrm{Mg} 2+$-independent phosphatidic acid phosphatase. J. Biol. Chem. 272:24572-24578. doi:10.1074/ jbc. 272.39 .24572

Kato, S. 1997. Thymic microvascular system. Microsc. Res. Tech. 38:287299. doi:10.1002/(SICI)1097-0029(19970801)38:3<287::AID-JEMT9> 3.0.CO;2-J

Kisanuki, Y.Y., R.E. Hammer, J. Miyazaki, S.C. Williams, J.A. Richardson, and M. Yanagisawa. 2001. Tie2-Cre transgenic mice: a new model for endothelial cell-lineage analysis in vivo. Dev. Biol. 230:230-242. doi:10 $.1006 /$ dbio. 2000.0106

Kono, M., M.L.Allende, and R.L. Proia. 2008. Sphingosine-1-phosphate regulation of mammalian development. Biochim. Biophys. Acta.1781:435-441.

Kühn, R., F. Schwenk, M. Aguet, and K. Rajewsky. 1995. Inducible gene targeting in mice. Science. 269:1427-1429. doi:10.1126/science.7660125
Lee, M.J., S. Thangada, K.P. Claffey, N. Ancellin, C.H. Liu, M. Kluk, M.Volpi, R.I. Sha'afi, and T. Hla. 1999. Vascular endothelial cell adherens junction assembly and morphogenesis induced by sphingosine-1-phosphate. Cell. 99:301-312. doi:10.1016/S0092-8674(00)81661-X

Liu, C.H., S. Thangada, M.J. Lee, J.R. Van Brocklyn, S. Spiegel, and T. Hla. 1999. Ligand-induced trafficking of the sphingosine-1-phosphate receptor EDG-1. Mol. Biol. Cell. 10:1179-1190.

Liu, G., S. Burns, G. Huang, K. Boyd, R.L. Proia, R.A. Flavell, and H. Chi. 2009. The receptor S1P1 overrides regulatory T cell-mediated immune suppression through Akt-mTOR. Nat. Immunol. 10:769-777. doi:10 $.1038 /$ ni.1743

Liu, G., K.Yang, S. Burns, S. Shrestha, and H. Chi. 2010. The S1P(1)-mTOR axis directs the reciprocal differentiation of $\mathrm{T}(\mathrm{H}) 1$ and $\mathrm{T}(\mathrm{reg})$ cells. Nat Immunol. 11:1047-1056. doi:10.1038/ni.1939

Lo, C.G., Y. Xu, R.L. Proia, and J.G. Cyster. 2005. Cyclical modulation of sphingosine-1-phosphate receptor 1 surface expression during lymphocyte recirculation and relationship to lymphoid organ transit.J. Exp. Med. 201:291-301. doi:10.1084/jem.20041509

López-Juárez, A., S. Morales-Lázaro, R. Sánchez-Sánchez, M. Sunkara, H. Lomelí, I. Velasco, A.J. Morris, and D. Escalante-Alcalde. 2011. Expression of LPP3 in Bergmann glia is required for proper cerebellar sphingosine-1-phosphate metabolism/signaling and development. Glia. 59:577-589.

Matloubian, M., C.G. Lo, G. Cinamon, M.J. Lesneski, Y. Xu, V. Brinkmann, M.L. Allende, R.L. Proia, and J.G. Cyster. 2004. Lymphocyte egress from thymus and peripheral lymphoid organs is dependent on S1P receptor 1. Nature. 427:355-360. doi:10.1038/nature02284

McCaughtry, T.M., M.S. Wilken, and K.A. Hogquist. 2007. Thymic emigration revisited. J. Exp. Med. 204:2513-2520. doi:10.1084/jem.20070601

Mizugishi, K., T.Yamashita, A. Olivera, G.F. Miller, S. Spiegel, and R.L. Proia. 2005. Essential role for sphingosine kinases in neural and vascular development. Mol. Cell. Biol. 25:11113-11121. doi:10.1128/MCB.25 .24.11113-11121.2005

Mori, K., M. Itoi, N.Tsukamoto, H. Kubo, and T. Amagai. 2007. The perivascular space as a path of hematopoietic progenitor cells and mature $\mathrm{T}$ cells between the blood circulation and the thymic parenchyma. Int. Immunol. 19:745-753. doi:10.1093/intimm/dxm041

Pappu, R., S.R. Schwab, I. Cornelissen, J.P. Pereira, J.B. Regard, Y. Xu, E. Camerer, Y.W. Zheng, Y. Huang, J.G. Cyster, and S.R. Coughlin. 2007. Promotion of lymphocyte egress into blood and lymph by distinct sources of sphingosine-1-phosphate. Science. 316:295-298. doi:10.1126/science .1139221

Pham, T.H., P. Baluk, Y. Xu, I. Grigorova, A.J. Bankovich, R. Pappu, S.R. Coughlin, D.M. McDonald, S.R. Schwab, and J.G. Cyster. 2010. Lymphatic endothelial cell sphingosine kinase activity is required for lymphocyte egress and lymphatic patterning. J. Exp. Med. 207:17-27. doi:10.1084/jem.20091619

Puneet, P., C.T.Yap, L. Wong,Y. Lam, D.R. Koh, S. Moochhala, J. Pfeilschifter, A. Huwiler, and A.J. Melendez. 2010. SphK1 regulates proinflammatory responses associated with endotoxin and polymicrobial sepsis. Science. 328:1290-1294. doi:10.1126/science.1188635

Pyne, S., K.C. Kong, and P.I. Darroch. 2004. Lysophosphatidic acid and sphingosine 1-phosphate biology: the role of lipid phosphate phosphatases. Semin. Cell Dev. Biol. 15:491-501. doi:10.1016/j.semcdb.2004.05.007

Renault, A.D., and R. Lehmann. 2006. Follow the fatty brick road: lipid signaling in cell migration. Curr. Opin. Genet. Dev. 16:348-354. doi:10 $.1016 /$ j.gde.2006.06.015

Rivera, J., R.L. Proia, and A. Olivera. 2008. The alliance of sphingosine-1phosphate and its receptors in immunity. Nat. Rev. Immunol. 8:753-763. doi:10.1038/nri2400

Roberts, R., V.A. Sciorra, and A.J. Morris. 1998. Human type 2 phosphatidic acid phosphohydrolases. Substrate specificity of the type $2 \mathrm{a}, 2 \mathrm{~b}$, and $2 \mathrm{c}$ enzymes and cell surface activity of the $2 \mathrm{a}$ isoform. J. Biol. Chem. 273:22059-22067. doi:10.1074/jbc.273.34.22059

Rosen, H., C. Alfonso, C.D. Surh, and M.G. McHeyzer-Williams. 2003. Rapid induction of medullary thymocyte phenotypic maturation and egress inhibition by nanomolar sphingosine 1-phosphate receptor agonist. Proc. Natl. Acad. Sci. USA. 100:10907-10912. doi:10.1073/ pnas. 1832725100 
Saba, J.D., and T. Hla. 2004. Point-counterpoint of sphingosine 1-phosphate metabolism. Circ. Res. 94:724-734. doi:10.1161/01.RES.0000122383 .60368 .24

Schwab, S.R., and J.G. Cyster. 2007. Finding a way out:lymphocyte egress from lymphoid organs. Nat. Immunol. 8:1295-1301. doi:10.1038/ni1545

Schwab, S.R., J.P. Pereira, M. Matloubian,Y. Xu,Y. Huang, and J.G. Cyster. 2005 Lymphocyte sequestration through S1P lyase inhibition and disruption of S1P gradients. Science. 309:1735-1739. doi:10.1126/science.1113640

Senda, K., K. Koizumi, O. Prangsaengtong, T. Minami, S. Suzuki, I. Takasaki, Y. Tabuchi, H. Sakurai, Y. Doki, T. Misaki, and I. Saiki. 2009. Inducible capillary formation in lymphatic endothelial cells by blocking lipid phosphate phosphatase-3 activity. Lymphat. Res. Biol. 7:69-74. doi:10.1089/1rb.2009.0005

Shiow, L.R., D.B. Rosen, N. Brdicková,Y. Xu, J. An, L.L. Lanier, J.G. Cyster, and M. Matloubian. 2006. CD69 acts downstream of interferon-alpha/ beta to inhibit S1P1 and lymphocyte egress from lymphoid organs. Nature. 440:540-544. doi:10.1038/nature04606

Srinivas, S., T. Watanabe, C.S. Lin, C.M. William, Y. Tanabe, T.M. Jessell, and F. Costantini. 2001. Cre reporter strains produced by targeted insertion of EYFP and ECFP into the ROSA26 locus. BMC Dev. Biol. 1:4 doi:10.1186/1471-213X-1-4

Ushiki, T. 1986. A scanning electron-microscopic study of the rat thymus with special reference to cell types and migration of lymphocytes into the general circulation. Cell Tissue Res. 244:285-298. doi:10.1007/BF00219204
Ushiki, T., and M. Takeda. 1997. Three-dimensional ultrastructure of the perivascular space in the rat thymus. Arch. Histol. Cytol. 60:89-99. doi:10 $.1679 /$ aohc. 60.89

Venkataraman, K., Y.M. Lee, J. Michaud, S. Thangada, Y. Ai, H.L. Bonkovsky, N.S. Parikh, C. Habrukowich, and T. Hla. 2008.Vascular endothelium as a contributor of plasma sphingosine 1-phosphate. Circ. Res. 102:669-676. doi:10.1161/CIRCRESAHA.107.165845

Wang, Y., M. Nakayama, M.E. Pitulescu, T.S. Schmidt, M.L. Bochenek, A Sakakibara, S. Adams, A. Davy, U. Deutsch, U. Lüthi, et al. 2010. EphrinB2 controls VEGF-induced angiogenesis and lymphangiogenesis. Nature. 465:483-486. doi:10.1038/nature09002

Wary, K.K., and J.O. Humtsoe. 2005. Anti-lipid phosphate phosphohydrolase3 (LPP3) antibody inhibits bFGF- and VEGF-induced capillary morphogenesis of endothelial cells. Cell Commun. Signal. 3:9. doi:10.1186/ 1478-811X-3-9

Weinreich, M.A., and K.A. Hogquist. 2008. Thymic emigration: when and how T cells leave home. J. Immunol. 181:2265-2270.

Yu, W., H. Nagaoka, M. Jankovic, Z. Misulovin, H. Suh, A. Rolink, F. Melchers, E. Meffre, and M.C. Nussenzweig. 1999. Continued RAG expression in late stages of B cell development and no apparent re-induction after immunization. Nature. 400:682-687. doi:10.1038/23287

Zachariah, M.A., and J.G. Cyster. 2010. Neural crest-derived pericytes promote egress of mature thymocytes at the corticomedullary junction. Science. 328:1129-1135. doi:10.1126/science.1188222 